\title{
Promoting financial inclusion for effective anti-money laundering and counter financing of terrorism (AML/CFT)
}

\author{
Abdullahi Y. Shehu
}

Published online: 13 January 2012

C The Author(s) 2012. This article is published with open access at Springerlink.com

\begin{abstract}
Financial inclusion" is the delivery of financial services at affordable costs, especially to the disadvantaged and low income populations. Financial inclusion has gained some importance in the last few decades as a result of findings on the impact of "financial exclusion" on development and especially its correlation to poverty. This paper arguesthat access to financial services contributes to human and economic development; and that financial inclusion and effective AML/CFT are complementary to ensure the safety, integrity and soundness of the financial system and the protection of depositors. It calls for the recognition of country specific characteristics of the derived segments of the society, the risks and national priorities in the application of AML/CFT measures, as well as how financial inclusion has been applied with flexible AML/CFT principles. It concludes that inclusive finance does not necessarily mean that everyone who is eligible uses each of the services, but they should be able to choose to use such services if they wish.
\end{abstract}

\section{Introduction}

The last three decades have witnessed an increasing global discourse directed at ensuring access to and availability of formal financial services to the active lowincome population at relatively affordable cost. It has been estimated that about 2.7 billion people or $70 \%$ of adults in developing countries and $20 \%$ in developed

Dr. Shehu is Director General of the Inter-Governmental Action Group against Money Laundering in West Africa (GIABA). GIABA is a Specialized Institution of the Economic Community of West African States (ECOWAS), as well as a Financial Action Task Force (FATF) Style Regional Body (FSRB) with its Headquarters in Dakar, Senegal.

A. Y. Shehu $(\bowtie)$

GIABA, Dakar, Senegal

e-mail: ayshehu@giaba.org 
countries do not have access to financial services [30]. More recently, the FATF [7] revealed that more than half of the world's population lack access to credit, insurance, savings accounts and other formal financial services. It estimates that less than $10 \%$ of the people who live with less US\$2 a day have access to formal financial services; and that the number of unbanked adults is estimated to be 2.7 billion (about $72 \%$ of adults) in the developing countries and 160 million (19\% of adults) in the developed countries.This unimaginably large marginalized segment of the society if not checked is likely to grow. On 29 December 2003, the United Nations Secretary General, Mr. Kofi Annan, observed that "the stark reality is that most poor people in the world still lack access to sustainable financial services, whether it is savings, credit or insurance. The great challenge before us is to address the constraints that exclude people from full participation in the financial sector. Together, we can and must build inclusive financial sectors that help people improve their lives". Thus, to stem the tide, evolution of an exclusive financial sector is the new mantra for poverty reduction, especially in the Least Developed Countries where often more than 90 percent of the population is excluded from the formal financial system. Nonetheless, such efforts are presumed to have the potential to derail the process of financial integration in the midst of inappropriate implementation of financial regulations especially application of antimoney laundering and combating the financing of terrorism (AML/CFT) controls.

The AML/CFT standards promote financial sector integrity and soundness and support the fight against crime. However, inappropriate implementation of these standards especially in developing economies has been identified as one of the several factors for excluding almost half of the world population from formal financial services. Poorly designed AML/CFT controls have the tendency to deny the unserved majority access to the formal financial services, undermine social and economic advancements and reduce regulatory and law enforcement capacity - a key means of strengthening integrity [13].

Financial inclusion and effective AML/CFT regime can and should be complementary,and pursue mutual benefits within national policy objectives. Countries should tap the flexibility embedded in the international AML/CFT standards to enable them to craft effective and appropriate controls. The challenge anyway, is on how to determine the right mix for the two- i.e., what level of protection is suitable for a particular financial environment?

Fortunately, a growing body of literature is beginning to emerge demonstrating the nexus between AML/CFT controls and financial inclusion. In particular, this paper draws from the outcomes of a recent study which also builds on earlier studies, including a CGAP analysis [14]. The First Initiative funded a five-country study [2] to analyze the effects of AML/CFT regulation on access to finance in Indonesia, Kenya, Mexico, Pakistan and South Africa. It concludes that AML/CFT measures can negatively affect access to, and use of, financial services if the measures are not carefully designed and applied. The study identifies factors that may exacerbate this impact, provides approaches on the design of appropriate AML/CFT controls that complement financial access policies, and suggests key design principles for AML/ CFT controls. Specifically, the study avers that:

- AML/CFT measures should be tailored to the domestic environment and the domestic risks of money laundering and financing of terrorism (ML/CF). 
- AML/CFT controls should be appropriate to the prevailing or potential risks.

- AML/CFT obligations should be matched to the capacity of both public and private institutions.

- Where institutional capacity is lacking, a plan should be developed to improve capacity and phase in AML/CFT obligations as institutional capacity increases.

- Law enforcement should be reserved as primary responsibility of the state, and law enforcement responsibility should not be unnecessarily shifted to private institutions. ${ }^{1}$

Inclusive finance aims to provide (1) access at a reasonable cost, to all households and enterprises, to the range of financial services for which they are "bankable", including access to markets, credits and financial education; (2) sound institutions, guided by appropriate internal management systems, industry performance standards, and performance monitoring by the market, including prudential regulation; (3) financial and institutional sustainability; and (4) multiplicity of providers of financial services, among others. Since the goal of financial inclusion is to attract all sorts of finance into the formal system (so that it can be properly regulated), it can be an effective mechanism for dealing with invisible finance. Thus, this paper seeks to enrich the stock of literature by highlighting in general how an effective AML/CFT regime can enhance and promote the attainment of an all-inclusive financial sector in developing countries with particular emphasis on West Africa. The paper is therefore organized as follows:an overview of financial inclusion is presented in section one. Section two reviews related literature on financial inclusion and its impact on economic development and AML/CFT. Section three discusses the implications of financial inclusion for effective AML/CFT program; while the challenges for developing countries are presented in section four. Section five concludes the paper with some recommendations.

\section{Literature review}

Financial inclusion

To properly contextualize financial inclusion, it is important to understand the meaning of financial exclusion. Financial exclusion could be defined as the prevailing conditions that prevent certain segments (social groups and/or individuals) of a society from gaining access to appropriate, affordable, fair and safe financial products and services provided by mainstream providers. As noted by Leyshon and Thrift [20], Mohan [24] and Ramji [26], the inability to access necessary financial services in an appropriate form may arise from self-exclusion or direct consequence by either the financial service providers (FSPs) or the government. Thus, financial exclusion has both demand and supply dimensions, the consequences of which include loss of opportunities for growth, loss of opportunities to thrive and borrow, risk of theft of finances which are kept outside the financial system, and increase in

\footnotetext{
${ }^{1}$ This author does not share the view that AML/CFT compliance obligation on financial institutions is a police duty nor does it impose unnecessary costs.
} 
cash transactions with its attendant consequences also. Therefore, financial inclusion is a multi-dimensional concept requiring a comprehensive definition that will address all key components. Unfortunately, until the late twentieth century, the poor were considered incapable of accessing financial assistance from formal financial organizations because they were assumed to lack the capacity to manage such resources [16]. Thus, the financial service needs of the poor were considered gross simplifications of the realities of their day-to-day experience and actions.

From the foregoing, we can safely refer to financial inclusion as the access of a portfolio of financial products and services for the majority of adult population with clear and precise information to meet the growing demand (especially of low income groups) under an appropriate regulatory framework. Unrestrained access to public goods and services is a sine qua non of an open and efficient system. It is argued that as banking services are in the public good, it is essential that availability of banking and payment services to the entire population without discrimination and inhibition is the prime objective of public policy. The term "financial inclusion" has gained importance since the early 2000 s, and is a result of findings about financial exclusion and its direct correlation to poverty. Financial inclusion is now a common objective for many central banks in developing countries.

More precisely, financial inclusion refers to the"universal access, at reasonable cost, to a wide range of financial services for everyone needing them, provided by a diversity of sound and sustainable institutions" [22]. ${ }^{2}$ Financial inclusion is also the provision of access to and usage of appropriate financial products and services to the 'most vulnerable group' of the society in a fair, transparent and cost-effective manner by the mainstream financial institutions [24]. As noted by Rangaragan Committee [27], Thorat [29] and Leeladhar [18], financial inclusion involves the provision of and access to financial services, such as payments infrastructure, remittance facilities, savings, credits, and insurance services provided by the formal financial system in a timely and adequate manner at affordable cost to the vast segments of vulnerable or disadvantaged groups. Financial inclusion is an aggregated "financial system that offers permanent access to a broad range of high quality financial services to the entire active population of a country at an affordable cost" [8].

From the foregoing, an inclusive financial system enhances the efficiency and welfare of citizens. Through financial inclusion, resources are efficiently allocated for productive purposes leading to reduction in cost of capital. Inaddition, an inclusive financial sector provides an avenue for secure and safe saving practices and it facilitates good day-to-day financial management practices. However, to ensure sustainable financial inclusion, the following requirements are basic: infrastructure, access to markets, appropriate production technology and availability of information.

The importance of an inclusive financial system is widely recognized in the policy circle, and recently, financial inclusion has become a policy priority in many countries. Initiatives for financial inclusion have come from the financial regulators,

\footnotetext{
2 These financial products and services include savings facility, credit and debit card access, electronic fund transfer, cheques and overdraft facilities, payment and remittance services, insurance and financial advisory services, pension and investment schemes, access to financial markets, micro credit during emergency, and all kinds of commercial loans.
} 
the governments and the banking industry. These initiatives are further corroborated in the communique issued by the G20 Financial Inclusion Working [31] when it affirmed as follows:

"We commit to improving access to financial services for the poor. We have agreed to support the safe and sound spread of new modes of financial service delivery capable of reaching the poor and, building on the example of micro finance. ... Working with the Consultative Group to Assist the Poor (CGAP) . . . and other international organizations, we will launch a G-20 Financial Inclusion Experts Group."

Legislative measures and financial sector reforms have been initiated in some countries. For example, in the United States, the Community Reinvestment Act (1997) requires banks to offer credit throughout their entire area of operation and prohibits them from targeting only the rich neighbourhoods. In France, the law on exclusion (1998) emphasizes an individual's right to have a bank account. In the United Kingdom, a "Financial Inclusion Fund" of $£ 120$ million was set up to help bring about financial inclusion and a 'Financial Inclusion Task Force' was launched in February 2005 to monitor progress on financial inclusion and make recommendations for further improvement.

In Malaysia, financial inclusion is a national agenda. The government commitment towards financial inclusion is reflected in the Central Bank Act 2009, where financial inclusion is legislated as an objective of Bank Negara Malaysia. The efforts to develop a more inclusive financial system have been fruitful. More than $80 \%$ of the Malaysian population currently has some form of savings account.

In West Africa, several governments have initiated programs designed to promote financial inclusion. For instance, the microfinance policy framework launched in 2005 by the Federal Government of Nigeria is targeted at bringing banking services at affordable cost to the doorsteps of the low income group. The main objective is mainstream the informal financial sector into the formal financial system. Senegal, Ghana, The Gambia, Mali, Burkina Faso and even the post conflict economies of Liberia and Sierra Leone have undertaken financial sector reforms designed to promote the integration of the informal financial sector with the formal.

The banking sector has also taken a lead role in promoting financial inclusion. In India, the Reserve Bank of India (RBI) has initiated several measures to achieve greater financial inclusion, such as facilitating 'no-frills' account and "General Credit Cards" for low deposit and credit. The German Bankers' Association introduced a voluntary code in 1996 providing for an 'everyman' current banking account that facilitates basic banking transactions. In South Africa, a low cost bank account called 'Mzansi' was launched for financially excluded people in 2004 by the South African Banking Association. Alternate financial institutions, such as microfinance institutions and Self-Help Groups have also been promoted in some countries in order to reach financial services to the excluded.

Developing countries have pioneered various cutting-edge financial inclusion policies, such as in the case of Agent Banking in Brazil and mobile money financial services in Kenya and the Philippines. These policies allow technological platforms to be used for cost-effective reach to the downstream savers. However, this knowledge has not been disseminated widely enough to allow for a scaling up and 
replication of these innovations in other countries. It is therefore apt that mechanisms that can disseminate this knowledge be established.

At the global level, the Alliance for Financial Inclusion (AFI) and the G-20 Financial Inclusion Experts Group, among others, have also taken steps to promote financial inclusion with view to reducing the prevalence of invisible finance. AFI brings together policy makers from developing countries to share cutting-edge financial inclusion policies. This has brought policy makers from Brazil and Colombia together to share their experiences on agent banking with Kenyan policy makers. Philippines' policy makers have also, under the umbrella of AFI, shared their experiences on mobile financial services with counterparts from Afghanistan. AFI is driven by policy makers who are members of its Steering Committee, which is currently chaired by the Governor of the Central Bank of Kenya. Table 1 below is an illustration of some initiatives aimed at mitigating financial exclusion and improving the implementation of AML/CFT measures.

In practical terms, the statistics show that some flexibility in the application of AML/CFT measures, without lowering the standards, would increase the chances of attracting more segments of the population into the formal financial system, and therefore, make it easier to monitor and detect any movement of funds or attempt to conceal the proceeds of crime. The information in the table also buttresses the flexibility in the implementation of the FATF Recommendations, particularly with regard to customer due diligence under R.5; monitoring of transactions by politically exposed persons (PEPs) under R.6; and records keeping under R.10 respectively. ${ }^{3}$

The impact of financial inclusion on economic development

The dominance of the financial system in developing countries by conventional financial institutions remains one of the 'stylized facts' of the analysis of financial repression [15]. Walter Bagehot (1873) and John Hicks [11] argue that the financial sector played a critical role in igniting industrialization in England by facilitating the mobilization of capital for "immense works." Joseph Schumpeter (1912) contends that well-functioning banks spur technological innovation by identifying and funding those entrepreneurs with the best chances of successfully implementing innovative products and production processes.

In contrast, Robinson [28], Lucas [21] and Chandavarkar [4] declare that "where enterprise leads, finance follows." According to them, economic development creates demands for particular types of financial arrangements, and the financial system responds automatically to these demands. Moreover, some economists just do not believe that the finance-growth relationship is important.For example, a collection of essays by the "pioneers of development economics," including three Nobel Laureates, did not mention finance [23].

Nonetheless, irrespective of the direction of the relationship between finance and economic development (i.e. whether growth-inducing or growth induced), what is paramount is the quality and efficiency of service delivery by the financial sector [3]. Therefore, the overarching question that we would strive to answer is-does a well-

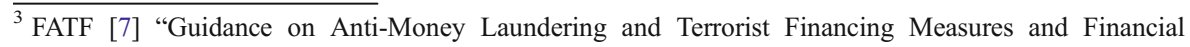
Inclusion" 


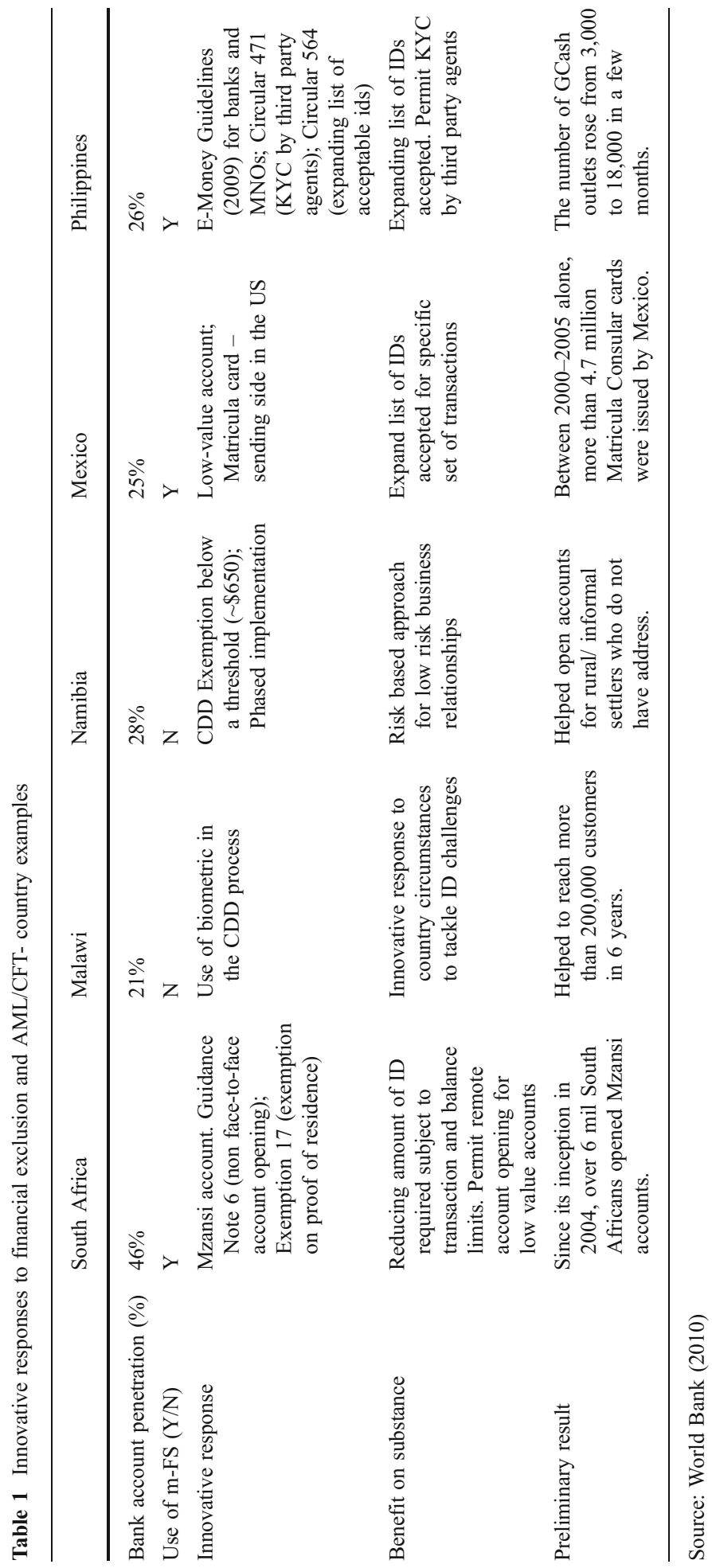


developed financial system serve the poor? There are ample theoretical justifications and empirical evidence indicating that a well-developed financial system can be an effective poverty alleviation tool.Broad access to financial services would smooth project financing, positively impacting growth and poverty alleviation [9]. Beck and de la Torre Agusto [1] also refer to the Schumpeterian process of 'creative destruction' whereby a well-developed financial system is able to allocate resources to efficient newcomers. The above positive stance was further corroborated in a study by King and Levine $[17]^{4}$ where they investigated the correlation between higher levels of financial development and faster current and future rates of economic growth. Using data from over 80 countries from 1960 through 1989, their findings were consistent with Schumpeter's view that the financial system can promote economic growth. A growing body of work would push even most sceptics toward the belief that the development of financial markets and institutions is a critical and inextricable part of the growth process and away from the view that the financial system is an inconsequential side show, responding passively to economic growth and industrialization.

Other research shows the importance of robust financial systems in economic development, especially those designed to uplift the poor. Finance has come a long way and is now attributed to being the 'brain' of an economic system and as such, most economies strive to make their financial systems more efficient.Thus, the new avenue for research in finance is 'making financial inclusion workable.' Honohan [12] in his research developed an index to measure access to finance in 160 countries. If the index is put on a world map, it can be clearly seen that advanced/ developed economies have higher indices. It is not implied that financial inclusion alone has led to development, but it is an important factor. Like any social science research, the findings have been diverse, but there seems to a consensus that finance promotes economic developmentat varying magnitude of impacts.

The reason for the renewed interest on financial inclusion in developing countries is straightforward: access to a well-functioning financial system can economically and socially empower poor and low income people and small and medium enterprises and can help them to better integrate into the economy of their countries. Access to financial services also, actively contributes to their human and economic development, to the economic growth of the countries where they live, and to the social safety net that can help protect them against economic shocks.

In summary, therefore, the correlations between financial inclusion and development are established through several channels: first, access to finance is access to markets that allow access to credit. Second, access to financial services promotes good savings/investment behaviour, facilitates capital accumulation and asset building and enables the poor to escape the poverty trap. Savings mobilization is critical to funding the investments needed to alleviate poverty, create wealth and employment in developing countries. Safe havens for savings by the poor reduce their vulnerability to periodic economic and social shocks. Strong and adequately supervised financial institutions will shield savers and citizens from instability triggered by investment uncertainties. Thus, the issue is what financial regulatory

\footnotetext{
${ }^{4}$ The relationship between financial system and economic development are also contained in the works of Greenwood and Jovanovic [10], Levine [19] and Eschenbach [6].
} 
framework in terms of design and application is appropriate to promote financial inclusion?

The AML/CFT framework and financial sector safety and soundness

The vulnerability of the financial sector to the vagaries of financial crimes, especially money laundering and terrorist financing, has accentuated the need to develop appropriate AML/CFT measures to reduce the impact of any financial quagmire on the financial system. Lack of financial inclusion, especially limited access to financial services, the use of informal channels, the prevalence of large informal service providers, among others, present difficulties in tracing and monitoring transactions, and thus leads to a weaker AML/CFT regime. Consequently, understanding the nexus between AML/CFT and financial inclusion will require an appreciation of the essence of an effective AML/CFT regime.AML/CFT measures are mechanisms put in place to facilitate an effective intermediation role of financial institutions, protect the integrity and soundness of the financial system, and ensure that only genuine economic activities are undertaken to promote economic growth and development. It is therefore important to establish a balance between mechanisms for money laundering prevention and the development of financial inclusion - in other words - simplified know your customer (KYC) and Customer Due Diligence (CDD) requirements for specific transactions, products and financial services if applied appropriately, represent a lower risk for money laundering. Developing a mobile banking system, for example, with the appropriate AML/CFT regulation, has the potential of increasing financial inclusion.

We believe that financial inclusion could enhance AML/CFT and ultimately mitigate invisible finance. The most comprehensive multi-dimensional and multi-sectoral approach in the global efforts to combat money laundering has been the initiative of the FATF as contained in what is now commonly known as the FATF $40+9$ recommendations. ${ }^{5}$ A higher level of international cooperation will reduce the vulnerability of the international financial system to ML/TF, and will improve global compliance with the standards. The FATF's primary role is to set and ensure the effective implementation of its standards. In many ways, the FATF standards aim to mitigate invisible finance as the standards seem to agree that "when a financial activity is carried out by a person or entity on an occasional or very limited basis (having regard to quantitative and absolute criteria) such that there is little risk of money laundering activity occurring, the FATF Standards allow a country to decide that the application of anti-money laundering measures is not necessary, either fully or partially. In strictly limited and justified circumstances, and based on a proven low risk of money laundering, a country may also decide not to apply some or all of the Forty Recommendations to some of the financial activities as defined by the FATF" [7].

\footnotetext{
5 The FATF is an inter-government body whose purpose is to develop and promote policies to combat money laundering. Established soon after the adoption of the UN Convention of 1988, the 40 recommendations were originally drawn in 1990. The recommendations were revised in 1996 and recently on 20 June 2003 to take into account the experiences gained over the previous years and to reflect the changes, which have occurred in the nature of money laundering. Currently, the FATF consists of 36 jurisdictions and two International Organizations. For further details on the FATF, see http://www.fatf-gafi.org
} 
The FATF 40+9 Recommendations provide a complete set of counter-measures against money laundering and terrorist financing, covering the criminal justice system and law enforcement, the financial system and its regulation, and international co-operation. The FATF Recommendations, although they do not represent a binding international convention, have been recognized, endorsed or adopted by over 182 countries and jurisdictions that have made a political commitment to combat money laundering and terrorist financing by implementing the FATF standards. The standards set out the principles of action by governments and competent authorities, and allow countries a measure of flexibility in implementing these principles according to their unique circumstances and constitutional frameworks.

In this regard, effective AML/CFT measures help to:

- Deny criminals the use of their illegal proceeds. In fact, the FATF AML/CFT measures are designed, among others, to remove the profit out of crime through confiscation, and to detect crime by following the money trail and targeting thirdparty or professional launderers who, through their services, assist criminals to retain the proceeds of their illegality. Another central focus of AML/CFT is the protection of the integrity of the financial system against abuse by criminals. Thus, the overarching principles of the recommendations are to prevent financial institutions from being misused or abused for the purposes of concealing invisible wealth or laundering the proceeds of crime and to detect such illicit activities through in-house banking information, systems and controls. This can help in providing a money trail (follow the criminal) and thus detecting the crimes.

- Identify the "mask" behind the Act (mostly third party issue or professional money launderers). The measures contemplated in the FATF recommendations target the upper echelon of criminal entities where the only connection to the crime is the money trail, thus, establishing beneficial ownership has become one of the core AML/CFT priorities.

- Facilitate coordinated approach to prosecution and enforcement. In short, the FATF 40 recommendations provide the general framework and instrumentalities on which the fight against money laundering should be anchored. The recommendations further spell out the specific requirements and roles of national legal systems, as well as the roles and obligations of financial institutions, particularly banks.

Within the context of mitigating invisible finance and the overall framework of financial systems regulation, the benefits of effective AML/CFT regimes are legion and would include:

a. Promoting good corporate governance and effective fiscal administration;

b. Facilitating integration of domestic financial systems into the global financial architecture;

c. Promoting financial transparency and encouraging the rule of law; and

d. Improving revenue collection as robust AML/CFT measures can impede tax fraud and evasion thereby increasing the sources of revenue to government.

The application of robust AML/CFT measures increases public confidence in financial institutions, thereby promoting market integration and investments through 
cross-border financial intermediation. Therefore, the deployment of effective AML/ CFT measures is beneficial at both the national and international levels. As noted by Princess Maxima [22], the underlying principles of effective AML/CFT controls are transparency and risk management. These principles ensure the safety, soundness and proper regulation of financial systems that promote consumer protection and provide an enabling environment for the development and usage of financial services. The demise of many giant financial institutions has been traced to lax regulation, and studies reveal a link between large shadow economies, weak states, organized crime and poverty. Nonetheless, it should be noted that it is difficult to track or capture transactions that take place within the informal system, thereby posing significant regulatory challenges.

The need to develop wellbalanced and proportionate AML/CFT regulatory frameworks, which reconcile financial inclusion's objectives with the AML/CFT requirements, is apparent. In order to meet these goals, any national AML/CFT regime needs to be tailored to the domestic circumstances. In particular, the level of development of the market, the financial culture, the structure and capacity of formal financial institutions, but also the existence of a national infrastructure for the identification of the population, the specific exposure of the country to terrorist organisations or the cross-border movements of population have to be taken into account.

\section{Implications of financial inclusion for effective AML/CFT program}

As earlier mentioned, financial inclusion and AML/CFT regimes are complementary, i.e., an effective AML/CFT regime can promote financial inclusion and also an allinclusive financial system could enhance the effectiveness of an AML/CFT framework. However, this depends on how integrated the financial system is.

In as much as effective AML/CFT framework is being put in place in a particular jurisdiction, it is important to be mindful of the prevailing financial environment. The objective of financial inclusion is that the individual clients, particularly low-income clients currently excluded from using formal financial services, should have access to, and on a sustainable basis use, financial services that are appropriate to their needs and provided by a wide array of financial service providers. Without a sufficient measure of financial inclusion, a country's AML/CFT system will thus safeguard the integrity of only a part of its financial system, leaving the informal and unregulated subsectors vulnerable to abuse, including the laundering of invisible finance.

In lesser developed economies, for example, where the larger part of the financial system is informal and unregulated, even if the FATF $40+9$ recommendations are implemented to the fullest on the formal financial sector, the expected outcome will remain limited.Poorly designed or inappropriate application of AML/CFT controls can, from a demand perspective, be barriers to accessing financial services.For instance, although national regulations may allow discretionary use of alternative documents to verify customers, institutions tend to limit discretion and the types of documents accepted. There is evidence suggesting that over-reliance on government ID has been a problem in many developing societies. And from the supply side, poorly applied CDD may involve more compliance costs for financial institutions. 
It should be remembered that a multitude of factors affect access to financial services, more so in countries with less developed financial systems. These factors include problems associated with the availability, reliability and verification of clients' identity, limited literacy, particularly financial literacy as against cultural practices and beliefs, level of income, terms of accessing financial services, like loans, which require certain collaterals, complicated procedures for account opening, residential identities, and overall lack of awareness. In the developing country context, the use of a risk-based and sequenced approach is most appropriate. Implementing the AML/CFT controls based on risk, country context, and capacity of regulators and financial service providers is the most effective approach. AML/CFT controls can be implemented in phases for unregulated providers, while gradually building capacity for increased levels of responsibility and controls measures. National authorities should therefore avoid regulatory uncertainty, balance compliance with actual risks, and thus, promote formal financial service delivery by eliminating the $a b$ initio, 'comparative advantage' of informal/unregulated providers; in short, they should simplify identification requirements without compromising standards.

A comprehensive and effective AML/CFT framework, together with timely implementation and effective enforcement, on the other hand, significantly reduce possibilities for abuse or misuse of the financial system for the purposes of laundering the proceeds of crime. And since crime proceeds is part of the 'invisible' finance, this author is of the view that a strengthened risk-based AML/CFT can effectively mitigate the impact of invisible finance on development. Despite the complementary role of financial inclusion in promoting AML/CFT, there remain significant challenges, especially for developing countries to truly enforce AML/ CFT measures at the same time as promoting financial inclusion.

\section{The challenges of AML/CFT and financial inclusion - recommendations}

The uniform and consistent application of the FATF standards is essential to make it more difficult for criminals to penetrate the system. Despite the guidance and best practices to assist in the implementation of AML/CFT standards, low capacity countries still face daunting challenges in doing so. ${ }^{6}$ The specific challenges of low income countries in implementing these standards can be surmised as follows:

- Competing priorities for scarce government resources

- Severe lack of resources and skilled workforce to implement government programs, including AML/CFT programs

- Weaknesses in legal institutions

- The dominance of the informal sector and a cash based economy

- Poor document and data retention systems; and

- In some cases, very small financial sector with limited exposure to the international financial system.

\footnotetext{
${ }^{6}$ For further details, see the FATF Best Practice Paper for Low Capacity Countries. Furthermore, the World Bank has developed a Strategic Implementation Planning (SIP) Framework, based on prioritization for low capacity countries to implement the FATF standards in a sequential manner.
} 
That notwithstanding, several countries have designed their AML/CFT controls to minimize adverse effects on financial access and to promote both financial inclusion and financial integrity. Whilst the challenges of promoting financial inclusion in the context of AML/CFT need not be repeated here, the following recommendations are proposed:

Domestication of AML/CFT measures The international AML/CFT standards especially the FATF $40+9$ Recommendations provide for countries and jurisdictions to adapt and adopt the measures based on their peculiar circumstances. Thus, countries should evolve policies that facilitate the implementation of the controls based on context-sensitive approach. The recommendations recognize the limit of a 'one size fits all' solution, that is, what works in one jurisdiction may not necessarily work in another. Therefore, the flexibility built into the FATF recommendations should be explored to design approaches that do not impede financial access. Country could adopt a proportionate approach involving the modification of client documentation and verification requirements, simplification of complex record keeping requirements, and launching new service channels. For low capacity countries, an incremental approach is recommended in the design and application of the international AML/CFT standards.

Consultative approach in $A M L / C F T$ design The fight against transnational crime requires a collective, coordinated, collaborative and cooperative approach by all stakeholders. The design of any AML/CFT controls should involve different actors across the various sectors of the economy to enhance ownership and guarantee completeness. To get the right mix of AML/CFT controls that promote financial inclusion, there is the need to consult with the private sector and other key actors so as to foster public/private sector dialogue to ensure practicality, proportionality of regulation/ supervision [30]. The involvement of the various stakeholders, including financial service providers, law enforcement agencies, financial regulators, the FIU, and other key role players (such as unregulated financial service providers, social welfare providers, ID agencies, and credit bureaux knowledgeable about social exclusion), is crucial because financial inclusion, and informal financial services, have important perspectives to share about ML/TF risk and appropriate risk control measures. It is important to reflect the different perspectives on AML/CFT measures, policies, and priorities to ensure that the country is able to adopt a clear, overarching policy that commits the government as a whole to effective and proportional controls.

National specific risk assessment An effective AML/CFT control system is that which promotes prioritization based on the perceived risk profile of the sectors of the economy. Thus, conducting national risk assessment will assist a country to design appropriate and proportional AML/CFT controls. The essence of the assessment is to attempt to determine the nature and scale of ML/FT risks and threats in the country, as well as weaknesses in the existing AML/CFT regimes. In particular, the assessment enables low capacity countries to optimally use their limited resources to address key risks. In tandem with FATF Recommendation 5 (R5), the assessment will enhance risk mapping to the various subsectors by institutions, products and services, and categories of clients. Governments should undertake balanced risk assessments that consider the relative levels of risks and vulnerabilities of high-, medium-, and low-risk activities as this will 
help in the formulation of proportional AML/CFT controls (De Koker 2009a). Risk assessments should be carried outon periodic basis and should be accompanied by an evaluation of the likely impact of proposed AML/CFT on service providers and clients. It should be noted that the establishment of a robust risk assessment programme is predicated on available information. Thus, all conceivable sources of information (government and development agencies and formal and informal financial serviceproviders) should be utilized. Countries are therefore advised to evolve AML/CFT measures that are proportionate to the risks and values that would comply with the FATF Standards and can attract more people to the formal financial system. In particular, reduced control for lower risk transaction as recognized by Essential Criteria 5.9 of the FATF Recommendation 5 (Customer Due Diligence) should be applied by countries.

Understand the causes and impact of financial exclusion To appreciate the potential impact of AML/CFT controls on financial inclusion, policy makers should understand the main causes of exclusion and therefore strive to identifythe groups affected. Understanding their demographic and psychographic characteristics is essential to the design of effective AML/CFT regimes. Therefore, there is the need to conduct national surveys such as theIntegrated Household Survey and Habits \& Attitudes Studies that can unravel the socio-economic behavior of the citizens especially the low-income groups. The outcomes of such research will provide both vertical and horizontal insights into the main drivers of financial exclusion and thus facilitate the design of robust AML/CFT regimes that promote financial inclusion.

Assess available resources to implement AML/CFT controls To ensure effective implementation of AML/CFT controls that support financial inclusion, policy makers should assess the capacity of financial service providers and financial sector regulators, as well as the coverage and integrity of the country's ID system. Careful analysis can help a country to design regulatory controls around the existing capacity of the relevant government agencies and service providers.

Sequencing and scaling AML/CFT controls Resource constraints facing low capacity countries place enormous challenges in meeting the FATF standards.Countries should ensure that primary processes are in place before secondary processes are imposed and that these processes are properly aligned to ameliorate the cost implications on AML/CFT controls. Therefore, due to limited resources, countries should sequence their regulatory program in phases using the risk-based approach. Implementing AML/CFT measures based on risk, country context, and capacity of regulators and financial service providers is the most effective approach. Implementation can also be in phases for unregulated providers in the following four increasing levels of responsibility and control measures: (1) the basic nonprudential registration requirement of financial service providers; (2) ensuring traceability of clients and transactions; (3) increasing requirements for client profiling; and (4) enhancing verification and interdiction.

Developing and improving national ID infrastructure The absence of reliable ID documentation or accessible verification sources complicates CDD processes, increases compliance costs, and undermines the effectiveness of AML/CFT 
measures. While a national ID document is not a precondition for an effective AML/CFT framework, there is the need to address shortcomings in the national ID infrastructure that might pose barriers to financial access. It is imperative to establish identification platforms that should make the documentation process simple, accessible and affordable.

Balancing controls with market requirements The development of AML/CFT controls should reflect commercial market logic as much as possible to promote cost effectiveness thereby eliminating distortions to market functioning. Thus, there is the need to achieve maximum scale through leverage of private capital and initiative, and that policies and interventions are designed to increase access to financial services without stifling private sector driven innovations. Also, AML/CFT controls should be designed to minimise compliance cost without undermining effectiveness.

Improvement in data collection, monitoring and evaluation To ascertain the gap in access to financial services, there is the need to improve a data collection process that would facilitate accountability of public policy implementation. As noted by Nduka [25] and Claessens et al. [5], the failure of most government policies is due to lack of in-built mechanism to monitor and evaluate the programs to ascertain the impact. Improving financial capability standards and access to objective advice will be a priority to ensure consumers are able to make the right decisions in difficult circumstances, and have the confidence to plan for the future.

Building capacity of regulators A major challenge in the design and application of AML/CFT is the level of skills and competences of the regulators. The flexibility provided by the international AML/CFT framework and the risk-based approaches are hardly utilized as expected due to poor understanding of these concepts. Thus, there is the need to scale up the technical skills of the regulators that will promote cross-agency harmonization of policies so as to avoid regulatory arbitrage and uncertainty that undermine sustainable access to financial services. In view of the recent global financial crisis, the existing statutory financial regulation objectives appear unsuitable for the purpose to deal with the post financial crisis challenges. Regulators should pursue four consumer protection objectives: consumer protection; promoting fair, efficient, competitive markets; promoting financial capability; and promoting financial inclusion and provision.

\section{The role of $\mathrm{GIABA}^{7}$ in promoting financial inclusion in West Africa}

The Inter-Governmental Action Group against Money Laundering in West Africa (GIABA) is mandated to develop strategies to protect the national economies and the financial and banking systems of signatory states against laundering the proceeds of

\footnotetext{
${ }^{7}$ GIABA is a specialized institution of the Economic Community of West Africa States (ECOWAS), as well as a FATF Style Regional Body (FSRB), based in Dakar whose members are the fifteen ECOWAS member States.
} 
crime, and combat the financing of terrorism. The economies of West African states are cash-dominated economies, and thus, vulnerable to problems of money laundering and terrorist financing. Yet, most of them lack the capacity to effectively tackle these problem, hence the need for a regional approach through GIABA.

In the last four years, GIABA has recorded significant progress in assisting member States to implement effective AML/CFT measures that promote financial inclusion. Specifically, the low level of compliance of the assessed member States shows that out of 11 evaluated countries, only two earned partially compliant (PC) rating on the FATF Recommendation 5 (R5: CDD - Customer Due Diligence) while the rest were rated Non-Compliant (NC). This result propelled GIABA to develop a model AML/CFT Compliance Manual that has been adopted by countries according to their jurisdictional peculiarities. Several capacity building activities have been executed for regulators, operators, law enforcement and the judiciary to improve their understanding of the requirements of AML/CFT.

In tandem with the overarching objective of the ECOWAS to promote and deepen regional economic integration, one of the main thrusts of GIABA is to support its smember States to implement effective AML/CFT measures that facilitate financial integration both domestically and internationally.In particular, GIABA is executing an accelerated program to assist member States in developing or revision of their National AML/CFT Strategy Framework to ensure prioritization, role identification and assignment to all stakeholders responsible for AML/CFT issues, optimal deployment of resources and proper sequencing of intervention activities.

In line with the recommendations of the World Bank Group [30], GIABA as a Financial Action Task Force (FATF) Style Regional Body (FSRB), will take on broad financial inclusion as a key contribution to effectiveness of AML/CFT regime. In preparing for the next round of mutual evaluations, assessors need to be sensitized to the correlation between financial inclusion and an effective AML/CFT regime. Also the mutual evaluation process and procedure may require improvement to recognize explicitly the issues in the methodology based on guidance or best practices papers on financial inclusion and the RBA paper on new payment methods. GIABA will liaise and collaborate with the FATF, FSRBs and other assessment bodies to ensure the application of the FATF $40+9$ Recommendations that promotes financial inclusion.

\section{Conclusion}

The need to bring in more people into the formal financial system cannot be overemphasized and the pursuit of financial inclusion and the combating of ML/TF can and should be viewed as complementary national policy objectives. We should banish the myth that financial integrity and financial inclusion are mutually exclusive and independent goals. When low-income clients are excluded from formal financial services, the goals of the AML/CFT requirements cannot be achieved. It is challenging to advance both objectives, but customising AML/CFT policies to the local context, and implementing them sensitively, can deliver significant benefits to clients and financial providers. Expectedly, promoting an inclusive finance would not only mitigate the preponderance of invisible finance, but 
would also facilitate growth with equity by, for example, inflating national income, promoting safe savings along with access to reliable services and making financial transactions easier, and ultimately eradicating poverty.

The importance of ensuring AML/CFT controls that promote financial inclusion was highlighted at the recent meeting in Korea of G20 Finance Ministers and Central Bank Governors through their call on "relevant international standard setting bodies to consider how they can further contribute to encouraging financial inclusion consistent with their respective mandates". One of the critical components of an effective AML/CFT system is financial inclusion. It is therefore of essence to evolve AML/CFT systems that would cover all segments of the financial system. The measures should ensure that financial services are formalized, regulated, accessible and used extensively by everyone needing them. By this, the reach and effectiveness of the AML/CFT controls are increased. It should be noted that the issue of financial inclusion presents a multi-dimensional challenge, of which AML/CFT requirements are an essential element. The adoption of AML/CFT controls is not the magic wand toward full realization of inclusive financial sectors, but it is nevertheless a milestone toward building an enabling framework. Strategies to overcome the inertia of financial inclusion will still need to be developed in the areas of accessibility and affordability of financial services, and design of adaptable products and services for the vulnerable and low income segments of our societies.

In conclusion, the following structural elements would therefore be critical in our efforts to implement an effective AML/CFT system:

a. Development of sound and sustainable financial sector policies;

b. Establishment and maintenance of functional public sector infrastructure;

c. Adoption of principles of transparency and good governance;

d. Enthronement of a proper culture of AML/CFT compliance that is shared and reinforced by all stakeholders (government, financial institutions, designated nonfinancial businesses and professions-DNFBPs, industry trade groups, and self-regulatory organizations-SROs);

e. Deployment of appropriate measures to combat corruption; and

f. Existence of a reasonably efficient criminal justice system, including a court system that facilitates proper enforcement of judicial decisions.

Open Access This article is distributed under the terms of the Creative Commons Attribution Noncommercial License which permits any noncommercial use, distribution, and reproduction in any medium, provided the original author(s) and source are credited.

\section{References}

1. Beck, T., \& de la Torre, A. (2006). The basic analytics of access to financial services. Mimeo.

2. Bester, H., Chamberlain, D., De Koker, L., Hougard, C., Short, R., Smith, A., \& Walker, R. (2008). Implementing FATF standards in developing countries and financial inclusion: Findings and guidelines. The FIRST initiative. Washington: The World Bank.

3. Cameron, R., Crisp, O., Patrick, H. T., \& Tilly, R. (1967). Banking in the early stages of industralisation. Oxford University Press. 
4. Chandavarkar, A. (1992). Of finance and development: neglected and unsettled questions. World Development, 20(1), 133-42.

5. Claessens, S., Honohan, P., \& Rojas-Suarez, L. (2009). Policy principles for expanding financial access. A report of the Centre for Global Development (CGD) Task Force on Access to Financial Services, October 2009.

6. Eschenbach, F. (2004). Finance and growth: A survey of the theoretical and empirical literature. Tinbergen Institute Discussion Paper No T1 2004-03912.

7. FATF (2011). Guidance on anti-money laundering and terrorist financing measures and financial inclusion.

8. Fernando, N. A. (2009). The state of financial inclusion in Asia: An overview. Presentation for 2009 AFI Global Policy Forum, Nairobi, Kenya, 14-16, September 2009.

9. Galor, O., \& Zeira, J. (1993). Income distribution and macroeconomics. Review of Economic Studies, $60,35-52$.

10. Greenwood, T., \& Jovanovic, B. (1990). Financial development, growth and the distribution of income. Journal of Political Economy, 98(5), 1076-1107.

11. Hicks, J. (1969). A theory of economic history. Oxford: Clarendon Press.

12. Honohan, P. (2005). Measuring microfinance access: Building on existing cross-country data. World Bank Policy Research Working Paper No. 3606.

13. Isern, J., \& De Koker, L. (2009). AML/CFT: Strengthening financial inclusion and integrity. Focus Notes 56. Washington: CGAP.

14. Isern, J., Porteous, D., Harandez-Coss, R., \& Egwuagu, C. (2005). AML/CFT regulation: Implications for the financial service providers that serve the poor people. Focus Notes 29. Washington: CGAP.

15. Johnson, S. (2005). Rural financial markets. In C. J. Green, C. H. Kirkpatrick, \& V. Murinde (Eds.), Finanve and development: Surveys of theory, evidence and policy (pp. 315-355). Edward Elgar.

16. Johnson, S., Hulme, D., \& Ruthven, O. (2005). Finance and poor people's livelihood. In C. J.Green, C. H. Kirkpatrick, \& V. Murinde (Eds.), Finanve and development: Surveys of theory, evidence and policy (pp. 277-303). Edward Elgar.

17. King, R. G., \& Levine, R. (1993). Finance, entrepreneurship and growth: theory and evidence. Journal of Monetary Economics, 32(3), 513-542.

18. Leeladhar, V. (2005). Taking banking services to the common man - financial inclusion. Commemorative Lecture by Deputy Governor Reserve Bank of India at the Fedbank Hormis Memorial Foundation at Ernakulam on December 2, 2005.

19. Levine, R. (1997). Financial development and economic growth: views and agenda. Journal of Economic Literature, $X X X V, 688-726$.

20. Leyshon, A., \& Thrift, N. (1995). Geographies of financial exclusion: financial abandonment in Britain and the United States. Transactions, Institute of British Geographers, New Series.

21. Lucas, R. E. (1988). On the mechanics of economic development. Journal of Monetary Economics, 22 (1), 3-42.

22. Maxima, P. (2010). AML/CFT and financial inclusion. Speech by Princess Maxima, UN Secretary General's Special Advocate at the Plenary of the Financial Action Task Force, Amsterdam, Kingdom of the Netherlands, June 20-25, 2010.

23. Meier, G. M., \& Seers, D. (1984). Pioneers in development. New York: Oxford University Press.

24. Mohan, R. (2006). Economic growth, financial deepening and financial inclusion. Paper presented at the Annual Bankers Conference. Hyderabad.

25. Nduka, O. E. (2010). Microfinance and poverty reduction in Nigeria: An evaluation of LAPO intervention. Unpublished Ph.D Thesis, Department of Economics \& Statistics, University of Benin, Nigeria.

26. Ramji, M. (2009). Financial inclusion in Gulbarga: Finding usage in access. IFMR Centre for Microfinance Working Paper Series No. 26, January 2009.

27. Rangarajan, C. (2008). Report of the committee on financial inclusion, chaired by Dr. C. Rangarajan. January 2008. Retrieved from: http://www.nabard.org/report_comfinancial.asp.

28. Robinson, J. (1952). The generalization of the general theory. In The rate of interest and other essays (pp. 67-142). London: Macmillan.

29. Thorat, U. (2007). Financial inclusion - the Indian experience. Speech at the HMT-DFID Financial Inclusion Conference, London, June 19, 2007.

30. World Bank Group (2010). Financial inclusion and AML/CFT.

31. WSBI (2009). AML/CFT rules and challenges of financial inclusion: World Savings Bank Institute (WSBI) experience and proposals to FATF. September, Doc 0565/09. 


\section{Further Reading}

1. Agrawal, A. (2008). The need for financial inclusion with an Indian perspective. Mumbai: IDBI Economic Research.

2. Carrington, I., \& Shams, H. (2006). Elements of an effective AML/CFT framework: Legal, regulatory and best institutional practices to prevent threats to financial stability and integrity. Washington, D.C.: Presentation at Seminar on Current Development in Monetary and Financial Law, October 23-27.

3. CGAP (2009). AML/CFT: Strengthening financial inclusion and integrity. CGAP Focus Note 56, August 2009.

4. FATF (2001). Forty recommendations on money laundering. Nine special recommendations on terrorist financing.

5. Genesis Analytics (2008). Implementing FATF standards in developing countries and financial inclusion: Findings and guidelines. Funded by FIRST Initiatives, May 2008.

6. Littlefield, E., Helm, B., \& David, P. (2006). Financial inclusion by 2015: Four scenarios for the future of microfinance. CGAP Focus Note No. 39.

7. Sarma, M. (2009). Index of financial inclusion. New Delhi: ICRIER Working Paper.

8. Sarma, M., \& Pais, J. (2008). Financial inclusion and development: A cross country analysis. New Delhi: ICRIER Working Paper.

9. Schott, P. A. (2006). Reference guide to anti-money laundering and combating the financing of terrorism. Second Edition and Supplement on Special Recommendation IX. World Bank and IMF.

10. Shehu, A. Y. (2010). Promoting financial sector stability through effective AML/CFT. Journal of Money Laundering Control. UK: Emerald Publishing.

11. Stern, N. (1989). The economics of development: a survey. Journal of Economics, 597-685. 